\title{
Effective dissection for rectal cancer with lateral lymph node metastasis based on prognostic factors and recurrence type
}

\author{
Hajime Morohashi ${ }^{1}$ (D) $\cdot$ Yoshiyuki Sakamoto ${ }^{1} \cdot$ Takuya Miura $^{1} \cdot$ Daichi Ichinohe $^{1} \cdot$ Kotaro Umemura $^{1}$. \\ Takanobu Akaishi $^{1} \cdot$ Kentaro Sato $^{1} \cdot$ Daisuke Kuwata $^{1} \cdot$ Keisuke Yamazaki $^{1} \cdot$ Taiichi Wakiya $^{1} \cdot$ Kenichi Hakamada $^{1}$
}

Accepted: 27 January 2021 / Published online: 1 February 2021

(C) The Author(s) 2021

\begin{abstract}
Purpose There are no reports showing the significance and effective range of dissection for patients with lateral lymph node metastasis (LLNM). This study aimed to investigate the indications for lateral lymph node dissection (LLND) in patients with LLNM based on prognostic factors and recurrence types.

Methods We reviewed 379 patients with advanced rectal cancer who were treated with total mesorectal excision plus LLND. We analyzed background factors and survival times of patients who had LLNM to determine prognostic factors and recurrence types. Results Pathological LLNM occurred in $44(11.6 \%)$. Among patients with LLNM, the predictors of poor prognoses, according to univariate analysis, were $>3$ node metastases, the presence of node metastasis on both sides, and spreading beyond the internal iliac lymph nodes. Moreover, LLNM beyond the internal iliac region was found to be an independent prognostic risk factor. Twenty-eight of the 44 patients with lateral lymph node metastasis (64\%) relapsed, 22 of whom had distant metastases and 11 of whom experienced local recurrences. Among the latter group, nine (20\%) and two (5\%) had recurrences in the central and lateral pelvis, respectively.

Conclusion The therapeutic benefit of resection was high, especially in patients with $\leq 3$ positive lateral lymph nodes, one-sided bilateral lymph node areas, and positive nodes localized near the internal iliac artery.
\end{abstract}

Keywords Lateral lymph node dissection $\cdot$ Lateral lymph node metastasis $\cdot$ Prognostic factor $\cdot$ Rectal cancer $\cdot$ Total mesorectal excision

\section{Introduction}

For advanced rectal cancer, when the tumor is located below the peritoneal reflection, the incidence of lateral lymph node metastasis (LLNM) is $14-30 \%$, and the prognosis for patients with LLNM is poor [1,2]. Therefore, it is important to improve the treatment outcomes in cases of LLNM in order to anticipate better treatment results with lower rectal cancer, in general. Total mesorectal excision (TME) is used to treat lower rectal cancer in hospitals worldwide [3, 4]. Since advanced rectal cancer is known to have more local recurrence when treated only with TME, national guidelines suggest that

Hajime Morohashi

hm2002@hirosaki-u.ac.jp

1 Department of Gastroenterological Surgery, Hirosaki University Graduate School of Medicine, Zaifu-cho 5, Hirosaki-shi 036-8562, Japan various preoperative treatment strategies precede TME in order to reduce local recurrence [5]. In Europe and the USA, preoperative chemoradiotherapy (CRT) and TME are the standard treatment methods, whereas the conventional treatment methods in Japan are TME and lateral lymph node dissection (LLND) [6]. Local recurrence of rectal cancer includes recurrence due to an inadequate circumferential resection margin (CRM) and recurrence due to lateral lymph node involvement. Although local recurrence caused by inadequate CRM cannot be compensated using LLND, the technique has an advantageous preventive effect on lateral lymph node recurrence. Conversely, there is little evidence of the therapeutic effect of CRT on LLNM. According to a Japanese study, incidences of lymph node metastasis in 2916 patients with rectal cancer accounted for $20.1 \%$. Among those who underwent LLND, however, the risk of pelvic recurrence was reduced by $50 \%$ and the 5 -year survival rate was expected to improve by $8-9 \%$ [1]. Therefore, in high-volume centers in Japan, the recommended standard procedure for advanced low rectal cancer is TME plus central D3 resection and bilateral LLND. 
In the JCOG0212 large-scale clinical trial that mainly targeted patients with clinically negative LLNM [7], the local recurrence rate in patients who underwent LLND was significantly lower than that of patients who did not undergo the procedure. LLND was particularly effective in suppressing local recurrence within the lateral pelvis, including the lateral lymph nodes [8]. Nonetheless, the results did not indicate that LLND improved overall survival. However, the therapeutic effect of LLND on patients with LLNM has not been clarified, and there is no prospective large-scale clinical trial showing this crucial data.

Previously, it has been reported that the dissection effect is high in cases with a small number of lateral lymph node metastases and in cases in which the metastases exist only in a limited area, but dissection does contribute to improved survival $[9,10]$. However, there is no report showing the significance and effective range of dissection for LLNM. For these reasons, our study aimed to investigate the indications for LLND based on prognostic factors and recurrence type in patients with LLNM.

\section{Materials and methods}

\section{Patients}

Between April 2001 and June 2017, 437 patients with low rectal cancer where tumor borders were below the peritoneal reflection underwent TME with LLND. The primary tumors were addressed pathologically with R0 resection at the Department of Gastroenterological Surgery, Hirosaki University. This study is from a single center, and the laboratory data or imaging data of all cases have been reviewed at a preoperative conference involving experienced surgeons. A total of 379 patients were included in our study after excluding 58 with distant metastases in the liver, lungs, or paraaortic lymph nodes (Fig. 1). The clinicopathological characteristics of patients were determined from clinical and histopathologic notes, and the tumor features and stages were classified according to the TNM classification system [11]. This retrospective study protocol was approved by the institutional Ethics Committee of Hirosaki University Hospital (No. 2018-120). Written informed consent was obtained from each patient prior to enrollment.

\section{Treatment strategies and surgical procedures}

LLND was indicated when the lower margin of the tumor was located below the peritoneal reflection and the tumor invaded the serosa, such patients underwent TME with LLND without preoperative CRT. Tumor progression, size, and position were evaluated using diagnostic imaging such as multidetector-row computed tomography (CT), magnetic resonance imaging (MRI), and barium enemas. The indications were determined in accordance with the guidelines of the Japanese Society for Cancer of the Colon and Rectum [5]. All patients underwent bilateral LLND after TME; proximal lymph node dissection along the lower mesenteric artery was also performed. The location of the lateral resection was identified according to the classifications set forth by the Japanese Society for Cancer of the Colon and Rectum [12], and LLND was performed as previously described [13]. The location of the LLLD was the internal iliac lymph node area and the obturator lymph node area [1]. Internal iliac vascular region lymph nodes dissection involved the removal of the fatty tissue on both the ventral side of the internal iliac vein and internal iliac artery from the bifurcated cords of the umbilical artery to the lateral urinary bladder. Obturator lymph node dissection entailed removal of the fatty tissue from the dorsal side of the external iliac vein to the tendinous arch of the levator ani muscle along the internal obturator muscle. Local and distant metastasis was diagnosed by CT, MRI, positron emission tomography, and elevated tumor markers, not biopsy.

The indication of adjuvant chemotherapy was pStage III. In principle, S-1 or UFT/LV therapy was to be started within 8 weeks after surgery. However, depending on the postoperative stage, the addition of oxaliplatin or even omission of postoperative adjuvant chemotherapy was at the discretion of the attending physician.

\section{Statistical analysis}

Survival analyses were performed using the Kaplan-Meier method with the log-rank test. Categorical variables are presented as patient percentages. $P$-values $<0.05$ were considered statistically significant. All statistical analyses were performed using SPSS version 24 (IBM Inc., Armonk, NY).

\section{Results}

\section{Clinicopathological details}

The attributes of all 379 patients are shown in Table 1. The average age was 62 years (range: $24-80$ years), and $70 \%$ were male. Lower rectal cancer $(\mathrm{Rb})$ was diagnosed in 326 patients $(86 \%)$, while the remaining subjects had upper rectal cancer (Ra). A pathologic wall depth of pT3 was found in 210 patients (55\%). Pathological mesorectal lymph node metastasis was observed in 158 patients (42\%) and pathological LLNM in $44(11.6 \%)$. Neoadjuvant chemotherapy was administered to 58 patients; none received CRT. The indication of neoadjuvant chemotherapy was determined in the same manner as 


\section{7 patients underwent TME with LLND}

\section{Adjusted by tumor of which the inferior border is located below the peritoneal reflection}

\section{8 ineligible patients \\ 32 liver metastasis \\ 16 paraaortic lymph node metastasis 10 lung metastasis}

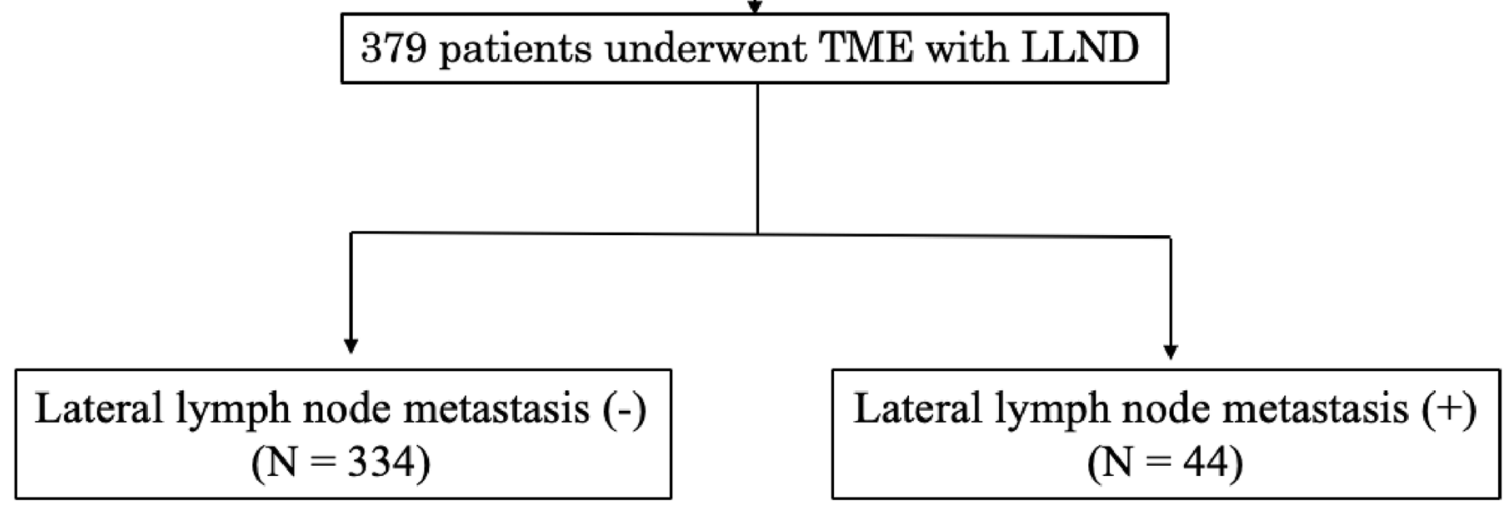

Fig. 1 Patients' profile

our new prospective study evaluating neoadjuvant chemotherapy without CRT for lower rectal cancer (unique trial no. jRCTs021180033). One hundred eighty-two patients $(48.0 \%)$ were given adjuvant chemotherapy. Table 2 shows the rate of positive LLNM for pT1 (3.7\%), pT2 (6.6\%), pT3 $(13.3 \%)$, and pT4 (15.2\%).

\section{Surgical outcomes}

Patient surgical outcomes are summarized in Table 3. The mean operation time was $243 \mathrm{~min}$, while the mean blood loss was $532 \mathrm{ml}$. Low anterior resection was the most common procedure (164 patients), and R0 excision was achieved for the primary lesion combined with proximal D3 node dissection in almost all patients. Thirty-eight patients underwent laparoscopic surgery, which tended to last longer than laparotomy, albeit with less bleeding. The median post-surgery hospitalization period was 26 days. In Japan, the length of hospital stay generally includes the period of medical treatment until food intake, defecation, and recovery of motor function after surgery, so the length of hospital stay tends to be longer than in Europe and the USA. Hospitalization can be significantly longer, especially when serious complications develop. Postoperative complications included anastomotic leakage in 57 (19\%) of the 299 patients in whom low anterior resection plus intersphincteric resection was performed. Cases with large tumors and cases with NAC tended to have more anastomotic insufficiency and intra-abdominal abscesses.

Perineal wound infections occurred in 27 (38\%) of the 80 patients who underwent the combination of abdominoperineal resection and total pelvic exenteration. The onset of abdominal wound infection was noted in 17 patients $(4.4 \%)$, ileus in $20(5.3 \%)$, and pelvic abscess in $26(6.9 \%)$. In addition to the patients in whom total pelvic exenteration was performed, 11 patients with dysuria $(2.6 \%)$ required a urinary catheter at the time of hospital discharge.

\section{Prognosis}

The median observation period was 60.4 months (range: 3696 months). Figure 2 shows relapse-free survival and overall survival. Among patients who underwent LLND, the 5-year survival rate was $55 \%$ and $85 \%$ for those with and without metastases, respectively $(P<0.01)$. Table 4 shows univariate and multivariate analysis of all patients who had TME and LLND. Among patients who underwent LLND, the predictors of poorer prognoses were identified as stage III disease, poorly differentiated tissue type, pT3-4, mesenteric lymph node metastasis, LLNM, venous invasion, or lymphatic invasion. On multivariate analysis, pT3-4 and lymphatic invasion were 
Table 1 Patient characteristics

\begin{tabular}{|c|c|}
\hline Characteristics & $n=379$ \\
\hline \multicolumn{2}{|l|}{ Sex } \\
\hline Male & 264 \\
\hline Female & 115 \\
\hline \multicolumn{2}{|l|}{ Age (year) } \\
\hline Median & 62 \\
\hline Range & $24-80$ \\
\hline \multicolumn{2}{|l|}{ Tumor location* } \\
\hline $\mathrm{Ra}$ & 53 \\
\hline $\mathrm{Rb}$ & 326 \\
\hline \multicolumn{2}{|l|}{ Tumor size (mm) } \\
\hline$<50$ & 175 \\
\hline$\geqq 50$ & 204 \\
\hline \multicolumn{2}{|l|}{ Clinical stage } \\
\hline II & 181 \\
\hline III & 198 \\
\hline \multicolumn{2}{|l|}{ Histological type } \\
\hline Well/moderate & 76 \\
\hline Mucinous/poor/signet & 303 \\
\hline \multicolumn{2}{|l|}{ Pathological T category } \\
\hline pT1 & 27 \\
\hline pT2 & 76 \\
\hline pT3 & 210 \\
\hline pT4 & 66 \\
\hline \multicolumn{2}{|c|}{ Pathological mesorectal LN metastasis } \\
\hline Absent & 221 \\
\hline Present & 158 \\
\hline \multicolumn{2}{|c|}{ Pathological lateral LN metastasis } \\
\hline Absent & 335 \\
\hline Present & 44 \\
\hline \multicolumn{2}{|l|}{ Vascular invasion } \\
\hline Absent & 163 \\
\hline Present & 216 \\
\hline \multicolumn{2}{|l|}{ Lymphatic invasion } \\
\hline Absent & 78 \\
\hline Present & 301 \\
\hline \multicolumn{2}{|c|}{ Neoadjuvant chemotherapy } \\
\hline No & 321 \\
\hline Yes & 58 \\
\hline \multicolumn{2}{|l|}{ Adjuvant chemotherapy } \\
\hline No & 197 \\
\hline Yes & 182 \\
\hline
\end{tabular}

* $R a$, tumor located above the peritoneal reflection; $R b$, tumor located the peritoneal reflection

independent risk factors of poorer survival. Among patients with LLNM, the predictors of poor prognoses according to univariate analysis were $>3$ node metastases, the presence of node metastasis on both sides, and spreading outside the internal iliac lymph node region. On multivariate analysis,
Table 2 Rate of LLNM for pT1, pT2, pT3 and pT4

\begin{tabular}{lll}
\hline & $\begin{array}{l}\text { Pathological T category } \\
(N=379)\end{array}$ & $\begin{array}{l}\text { Lateral lymph node metastasis } \\
(N=44)\end{array}$ \\
\hline pT1 & 27 & $1(3.7 \%)$ \\
pT2 & 76 & $5(6.6 \%)$ \\
pT3 & 210 & $28(13.3 \%)$ \\
pT4 & 66 & $10(15.0 \%)$ \\
\hline
\end{tabular}

LLNM outside the internal iliac and obturator lymph node area was found to be an independent prognostic risk factor (Table 5).

\section{Recurrence}

Figure 3 shows a flowchart of recurrence in patients with LLNM. Twenty-eight of the 44 patients with LLNM (64\%) relapsed; 11 experienced local recurrences (nine in the central pelvis and two in the lateral pelvis) while 22 (79\%) had distant recurrences. Figure 4 shows a flowchart of recurrence in patients without LLNM. Seventy-nine of the 335 patients with LLNM (23.6\%) relapsed; 32 experienced local recurrences (30 in the central pelvis and two in the lateral pelvis) while $61(77.2 \%)$ had distant recurrences.

Table 3 Operative outcomes

\begin{tabular}{ll}
\hline Variables & Value \\
\hline Operative procedure & \\
Low anterior resection & 164 \\
Intersphincteric resection & 135 \\
Hartmann's procedure & 8 \\
Abdonimoperitoneal resection & 67 \\
Total pelvic exenteration & 5 \\
Open or laparoscopic assisted & \\
Open surgery & 341 \\
Laparoscopic assisted & 38 \\
Operation time (min) (range) & $243(86-633)$ \\
Total blood loss (ml) (range) & $532(5-2500)$ \\
Postoperative hospital days (day) (rage) & $26(8-144)$ \\
Operative complication (cases) & \\
Anastomotic leakage & $57(19 \%)$ \\
Perineal wound infection & $27(33 \%)$ \\
Abdominal wound infection & $17(4.4 \%)$ \\
Paralytic ileus & $18(4.7 \%)$ \\
Bowel obstruction & $20(5.3 \%)$ \\
Urinary retention requiring & $11(2.6 \%)$ \\
self-catheterization at discharge & $3(0.8 \%)$ \\
Bleeding & $26(6.9 \%)$ \\
\hline Pelvic abscess &
\end{tabular}


Table 4 Prognostic factors of lateral lymph node dissection

\begin{tabular}{|c|c|c|c|c|c|c|}
\hline \multirow[t]{2}{*}{ Variables } & \multicolumn{3}{|c|}{ Univariate analysis } & \multicolumn{3}{|c|}{ Multivariate analysis } \\
\hline & HR & $95 \% \mathrm{CI}$ & $P$ value & $\mathrm{HR}$ & $95 \% \mathrm{CI}$ & $P$ value \\
\hline Sex & & & 0.793 & & & \\
\hline Male & 1 & & & & & \\
\hline Female & 0.934 & $0.558-1.562$ & & & & \\
\hline Age (year) & & & 0.378 & & & \\
\hline$\leqq 60$ & 1 & & & & & \\
\hline$>60$ & 0.807 & $0.501-1.299$ & & & & \\
\hline Tumor location* & & & 0.761 & & & \\
\hline $\mathrm{Ra}$ & 1 & & & & & \\
\hline $\mathrm{Rb}$ & 0.907 & $0.485-1.696$ & & & & \\
\hline Tumor size (mm) & & & 0.799 & & & \\
\hline$<50$ & 1 & & & & & \\
\hline$\geqq 50$ & 1.065 & $0.658-1.722$ & & & & \\
\hline Clinical stage & & & 0.001 & & & 0.065 \\
\hline II & 1 & & & 1 & & \\
\hline III & 5.586 & $2.923-10.676$ & & 2.355 & $0.949-5.846$ & \\
\hline Histological type & & & 0.002 & & & 0.073 \\
\hline Well/moderate & 1 & & & 1 & & \\
\hline Mucinous/poor/signet & 3.418 & $1.371-8.522$ & & 2.314 & $0.925-5.790$ & \\
\hline Operative procedure & & & 0.052 & & & \\
\hline Sphincter preservation/Hartmann & 1 & & & & & \\
\hline $\mathrm{APR} / \mathrm{TPE}$ & 1.727 & $0.996-2.993$ & & & & \\
\hline $\mathrm{pT}$ & & & 0.001 & & & 0.008 \\
\hline pT0-2 & 1 & & & 1 & & \\
\hline pT3-4 & 6.324 & $2.302-17.371$ & & 3.98 & $1.440-11.003$ & \\
\hline Pathological mesorectal LN metastasis & & & 0.001 & & & 0.121 \\
\hline Absent & 1 & & & 1 & & \\
\hline Present & 5.177 & $2.954-9.074$ & & 1.888 & $0.931-2.869$ & \\
\hline Pathological lateral LN metastasis & & & 0.001 & & & 0.087 \\
\hline Absent & 1 & & & 1 & & \\
\hline Present & 3.145 & $1.834-5.394$ & & 1.635 & $0.931-2.869$ & \\
\hline Vascular invasion & & & 0.001 & & & 0.497 \\
\hline Absent & 1 & & & 1 & & \\
\hline Present & 1.944 & $1.200-3.150$ & & 1.200 & $0.709-2.029$ & \\
\hline Lymphatic invasion & & & 0.001 & & & 0.022 \\
\hline Absent & 1 & & & 1 & & \\
\hline Present & 2.575 & $1.599-4.149$ & & 1.843 & $1.092-3.111$ & \\
\hline Neoadjuvant chemotherapy & & & 0.760 & & & \\
\hline No & 1 & & & & & \\
\hline Yes & 1.140 & $0.492-2.640$ & & & & \\
\hline
\end{tabular}

*Ra, tumor located above the peritoneal reflection; $R b$, tumor located the peritoneal reflection

\section{Discussion}

Examination of prognostic factors revealed that metastases of $>3$ nodes, the presence of node metastasis on both sides, and spreading outside the internal iliac lymph node region led to a poor prognosis. LLNM outside the internal iliac and obturator lymph node area, in particular, was found to be an independent prognostic risk factor. The indication of LLND for patients with LLNM differs depending upon whether the LLNM is considered to consist of local metastases that can be cured by resection or distant metastases that cannot be controlled locally [14]. There are various opinions on whether and how 
Table 5 Prognostic factors of lateral lymph node metastasis

\begin{tabular}{|c|c|c|c|c|c|c|}
\hline \multirow[t]{2}{*}{ Variables } & \multicolumn{3}{|c|}{ Univariate analysis } & \multicolumn{3}{|c|}{ Multivariate analysis } \\
\hline & HR & $95 \% \mathrm{CI}$ & $\begin{array}{l}P \\
\text { value }\end{array}$ & HR & $95 \% \mathrm{CI}$ & $\begin{array}{l}P \\
\text { value }\end{array}$ \\
\hline Sex & & & 0.289 & & & \\
\hline Male & 1 & & & & & \\
\hline Female & 0.603 & $0.237-1.536$ & & & & \\
\hline Age (year) & & & 0.662 & & & \\
\hline$\leqq 60$ & 1 & & & & & \\
\hline$>60$ & 1.223 & $0.495-3.021$ & & & & \\
\hline Tumor location* & & & 0.571 & & & \\
\hline $\mathrm{Ra}$ & 1 & & & & & \\
\hline $\mathrm{Rb}$ & 21.418 & $0.001-8565.6$ & & & & \\
\hline Tumor size (mm) & & & 0.808 & & & \\
\hline$<50$ & 1 & & & & & \\
\hline$\geqq 50$ & 1.12 & $0.449-2.792$ & & & & \\
\hline Clinical stage & & & 0.343 & & & \\
\hline II & 1 & & & & & \\
\hline III & 2.655 & $0.354-19.935$ & & & & \\
\hline Histological type & & & 0.830 & & & \\
\hline Well/moderate & 1 & & & & & \\
\hline Mucinous/poor/signet & 0.873 & $0.253-3.013$ & & & & \\
\hline Operative procedure & & & 0.593 & & & \\
\hline Sphincter preservation/Hartmann & 1 & & & & & \\
\hline APR/TPE & 1.283 & $0.513-3.213$ & & & & \\
\hline pT & & & 0.274 & & & \\
\hline pT0-2 & 1 & & & & & \\
\hline pT3-4 & 0.274 & $0.522-9.909$ & & & & \\
\hline Pathological mesorectal LN metastasis & & & 0.269 & & & \\
\hline Absent & 1 & & & & & \\
\hline Present & 25.179 & $0.082-7722.9$ & & & & \\
\hline Pathological lateral LN metastasis & & & 0.008 & & & 0.272 \\
\hline$<3$ & 1 & & & 1 & & \\
\hline$\geqq 3$ & 0.308 & $0.129-0.732$ & & 1.548 & $0.710-3.377$ & \\
\hline Pathological lateral LN metastasis & & & 0.006 & & & 0.866 \\
\hline Unilateral & 1 & & & 1 & & \\
\hline Bilateral & 3.258 & $1.401-7.575$ & & 1.068 & $0.499-2.284$ & \\
\hline Pathological lateral LN metastasis & & & 0.048 & & & 0.016 \\
\hline $\begin{array}{l}\text { Internal iliac vascular region lymph } \\
\text { nodes area }\end{array}$ & 1 & & & 1 & & \\
\hline Other obturator lymph node area & 2.355 & $1.019-5.442$ & & 2.7 & $1.199-6.079$ & \\
\hline Vascular invasion & & & 0.365 & & & \\
\hline Absent & 1 & & & & & \\
\hline Present & 1.543 & $0.604-3.939$ & & & & \\
\hline Lymphatic invasion & & & 0.537 & & & \\
\hline Absent & 1 & & & & & \\
\hline Present & 1.887 & $0.251-14.180$ & & & & \\
\hline Neoadjuvant chemotherapy & & & 0.479 & & & \\
\hline No & 1 & & & & & \\
\hline Yes & 1.646 & $0.479-5.655$ & & & & \\
\hline
\end{tabular}

* Ra, tumor located above the peritoneal reflection; $R b$, tumor located the peritoneal reflection 

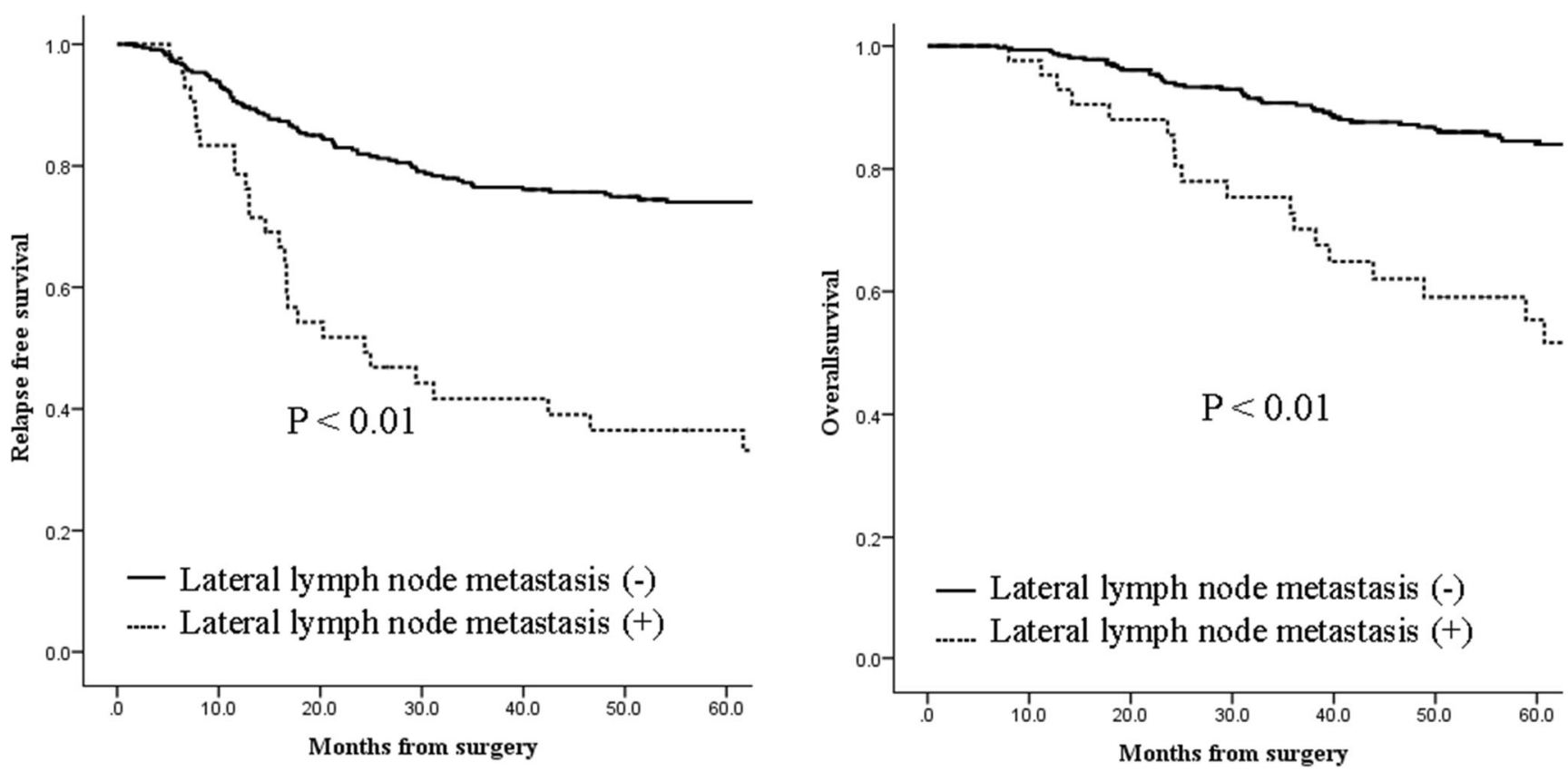

Fig. 2 Relapse-free survival (a) and overall survival (b) rate of patients with and without lateral lymph node metastasis

bilateral LLND should be performed for LLNM [15], as there are other options, such as using selective LLND only for swollen lymph nodes [16] and omitting LLND, substituting CRT [17]. The therapeutic benefits of LLND for patients with LLNM have not yet been definitively determined.

One of the essential goals of treating rectal cancer is to reduce the local recurrence rate, and procedures to this effect are being optimized in various countries worldwide. In Japan, TME with autonomic nerve-sparing LLND has been performed for a long time $[18,19]$. This differs from the therapeutic strategies employed in Europe and the USA, where the standard treatment methods are preoperative CRT followed by
TME. The reason for this is that the local rectal lymphatic system below the inverted peritoneum flows in three directions: upward, laterally, and downward [20]. In addition to dissecting the regional and central lymph nodes along the inferior mesenteric artery, in Japan, it is thought that R0 resection is possible by dissecting the region along the lateral lymph flow [9].

LLND in patients with rectal cancer has been reported to reduce local recurrence rates and increase 5-year survival rates [21, 22]. Conversely, a meta-analysis of 20 patients indicated no improvement in prognosis following lateral LLND, although an increase in urogenital system complications was
Fig. 3 Recurrence rate of local and distant metastasis with lateral lymph node metastasis

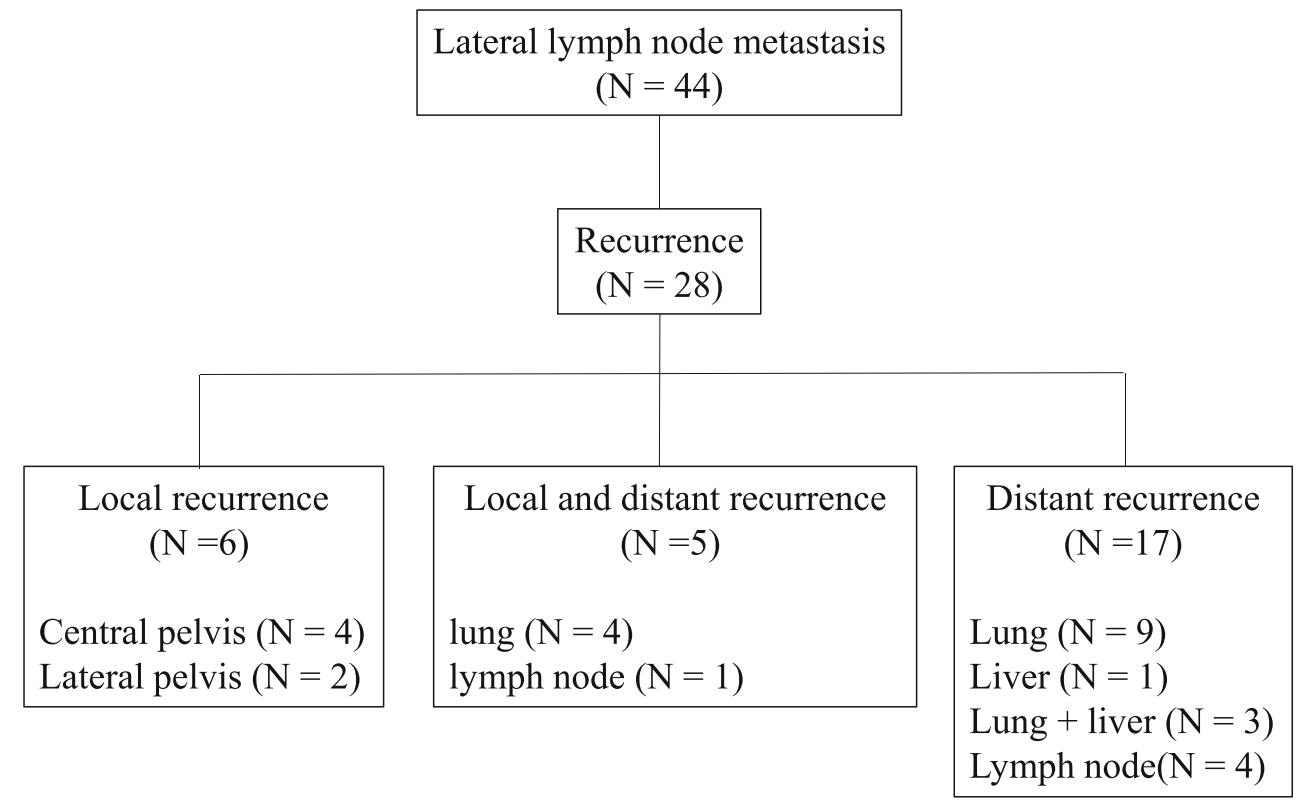


Fig. 4 Recurrence rate of local and distant metastasis without lateral lymph node metastasis

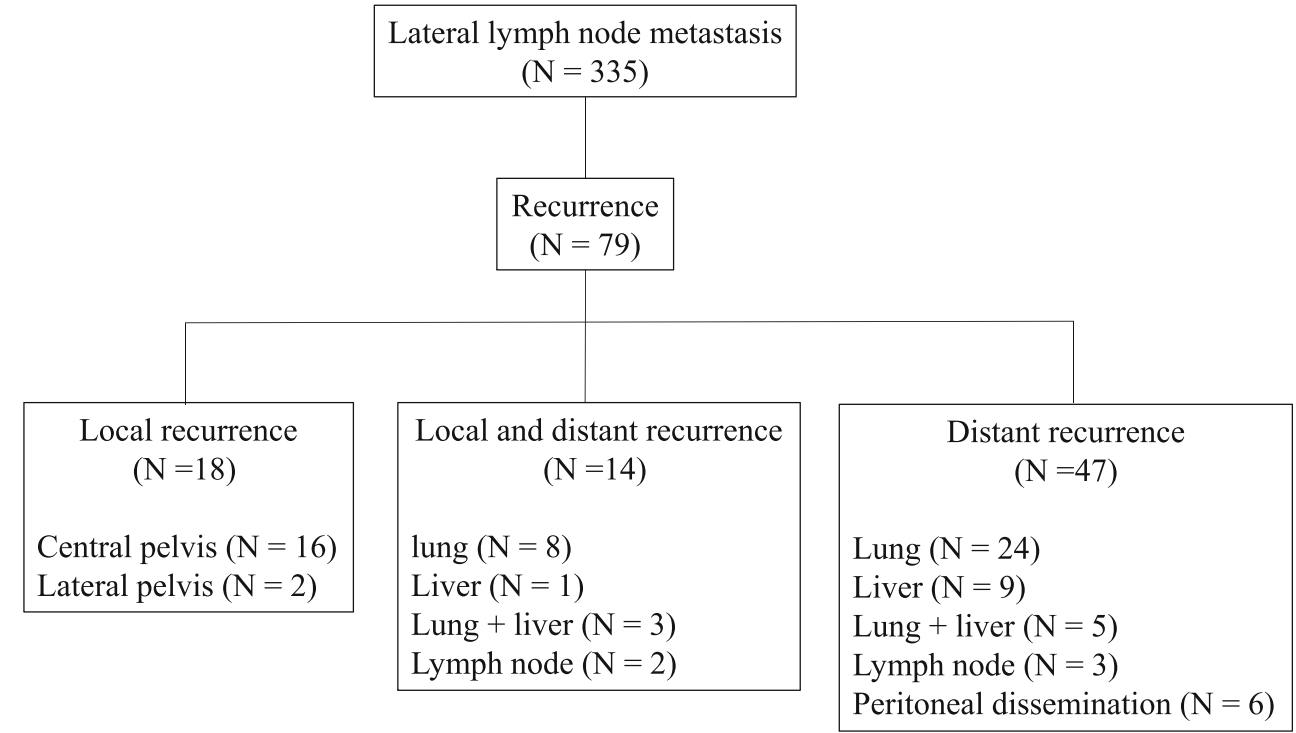

observed [23, 24]. However, many Japanese surgeons use autonomic nerve-preserving LLND techniques, which is more likely to prevent such complications [15]. Among patients enrolled in the JCOG0212 trial [8], there was no significant increase in the rate of urinary dysfunction for those who underwent LLND compared with other procedures. The incidence of urinary dysfunction is associated with tumor location and blood loss [25]. More recently, robot-assisted lateral resection has been reported to reduce urogenital system complications caused by this procedure [26].

On the other hand, preoperative CRT is reportedly effective in controlling local recurrence but does not necessarily improve the prognosis [27]. There are also reports of adverse events such as high incidences of urogenital system disorders, as well as radiation-induced venous thrombosis, intestinal obstruction, fistula development, transcervical fractures, and anal function failures [28, 29]. Akiyoshi et al. reported that $66 \%$ of patients who were diagnosed with metastasis of the lateral lymph nodes via preoperative imaging examinations and who underwent LLND after CRT were found not to be cancer-free pathologically [16]. It appears that CRT is not always sufficient to treat enlarged metastatic lateral lymph nodes, as it cannot completely eliminate lateral lymph node metastases. Hence, LLND is the most useful approach to achieving local control in patients with enlarged metastatic lateral lymph nodes, whereas preoperative CRT is not recommended [30].

In this study, among patients who underwent LLND with metastases, the 5-year survival rate was $55 \%$ and the rate of LLNM recurrence was 64\%; among those with recurrences, $25 \%$ were local $(5 \%$ in the lateral pelvis and $20 \%$ in the central pelvis) and $79 \%$ were distant. Although local control within the lateral lymph node region was reasonably achieved following LLND, it is also necessary to aim for high-quality TME to reduce the risk of recurrence in the central pelvis. $\mathrm{R} 1$ resection is one of the risk factors of local recurrence. However, in this study, the subjects were patients who had $\mathrm{R} 0$ resections. Of the 197 patients who did not undergo adjuvant chemotherapy, 24 $(12.2 \%)$ relapsed. Since there is a risk of recurrence in cases with pStage II or lower, as well, it is necessary to consider the indication of adjuvant chemotherapy.

In general, the 5-year survival rate for patients with stage IV rectal cancer is 10-20\% unless the metastatic tumors are excised [31, 32]. Our study showed that patients with lateral lymph node metastases had a better prognosis with LLND than that of stage IV patients. Kanemitsu et al. reported that, according to the index of the estimated benefits derived from LLND, dissection of the internal iliac and obturator nodes yielded similar therapeutic benefits as those expected from the dissection of the superior rectal artery lymph nodes [15]. Furthermore, Tamura et al. reported no oncological benefit from performing LLND in patients with stage IV disease who had both lateral and distant lymph node metastases [33]. Oh et al. reported that $59.1 \%$ of their patients with lateral lymph node metastases who underwent LLND also had distant metastases and poor prognoses [34]. LLND may be beneficial for patients with LLNM, but its indication is restricted if cancer cells have potentially spread to other areas of the body.

It is very difficult to determine the presence of LLNM before surgery. A previous study identified the risk factors for LLNM as female sex, lower rectal cancer location, lymphatic invasion, venous invasion, wall progression, and paraintestinal lymph node metastasis $\geq 5 \mathrm{~mm}$ in width on magnetic resonance imaging [35]. Another group found that the diagnostic ability for LLNM is more promising at a short axis of $5 \mathrm{~mm}$ than it is at $10 \mathrm{~mm}$ [36]. However, there are reports of pathological lymph node metastases being found in 
approximately half of the lymph nodes that were judged to be small $(<5 \mathrm{~mm})$ on diagnostic imaging $[37,38]$. It may be difficult to evaluate the presence or absence of LLNM based only on the size of preoperative imaging. Hence, it may be necessary to more closely evaluate the shape and integrity of the lymph nodes in addition to the size for a more thorough analysis of the presence of metastases. Our research group recently reported that a combination of size-based diagnoses and dual-energy CT may increase the accuracy of a preoperative diagnosis of LLNM [39].

When accurate preoperative determination of LLNM is difficult, but metastasis is suspected, LLND is an appropriate approach for lower rectal cancer. The therapeutic effect of resection is considered high, especially in patients with $\leq 3$ positive lateral lymph nodes, nodes on one side of the bilateral lymph node area, or nodes localized near the internal iliac artery. Local control is achievable for patients with LLNM following LLND; however, distant recurrence is frequent in LLNM. Given the high proportion of distant recurrences, a strategy that considers potent systemic chemotherapy for distant metastases is necessary to improve the survival rate of patients with lateral lymph node metastases.

The limitation of our research is that it was a retrospective study, and the study sample of LLNM $(n=44)$, which we used for determining risk factors, was small. Moreover, owing to the long study period, the laparotomy/laparoscopy procedures, chemotherapy regimens, scopes of lymph node resection, and treatment durations have evolved over the course of the study and were therefore inconsistent across the entire cohort. In Japan, traditionally, the mesorectum is peeled away and excised, after which it is examined for lymph node metastasis. Then, the rectum is opened and formalin is used to determine the extent of cancer. Thus, in this study, it was difficult to make an accurate pathological evaluation of CRM or TME quality on resected specimens in the same manner as in Europe and North America.

\section{Conclusion}

Based on the prognostic factors and the recurrence types of patients with LLNM, it was thought that LLND could control the metastasis limited to the internal iliac vessel region with less than three metastases on one side. It was considered necessary to treat LLNM as a systemic disease in cases in which metastasis spread further.

Availability of data and material Not applicable. Code availability Not applicable.

Author contributions All authors contributed to the study conception and design. All authors read and approved the final manuscript.

\section{Declarations}

Ethics approval The study protocol was approved by the Institutional Ethics Committee of Hirosaki University Hospital (No. 2018-120)

Consent to participate Informed consent was obtained from all individual participants included in the study.

Consent for publication Informed consent was obtained from all individual participants included in the study.

Conflict of interest The authors declare no conflict of interest.

Open Access This article is licensed under a Creative Commons Attribution 4.0 International License, which permits use, sharing, adaptation, distribution and reproduction in any medium or format, as long as you give appropriate credit to the original author(s) and the source, provide a link to the Creative Commons licence, and indicate if changes were made. The images or other third party material in this article are included in the article's Creative Commons licence, unless indicated otherwise in a credit line to the material. If material is not included in the article's Creative Commons licence and your intended use is not permitted by statutory regulation or exceeds the permitted use, you will need to obtain permission directly from the copyright holder. To view a copy of this licence, visit http://creativecommons.org/licenses/by/4.0/.

\section{References}

1. Sugihara K, Kobayashi H, Kato T, Mori T, Mochizuki H, Kameoka S, Shirouzu K, Muto T (2006) Indication and benefit of pelvic sidewall dissection for rectal cancer. Dis Colon Rectum 49:16631672. https://doi.org/10.1007/s10350-006-0714-z

2. Fujita S, Yamamoto S, Akasu T, Moriya Y (2003) Lateral pelvic lymph node dissection for advanced lower rectal cancer. Br J Surg 90:1580-1585. https://doi.org/10.1002/bjs.4350

3. West NP, Hohenberger W, Weber K, Perrakis A, Finan PJ, Quirke P (2010) Complete mesocolic excision with central vascular ligation produces an oncologically superior specimen compared with standard surgery for carcinoma of the colon. J Clin Oncol 28:272278. https://doi.org/10.1200/JCO.2009.24.1448

4. Wibe A, Rendedal PR, Svensson E, Norstein J, Eide TJ, Myrvold HE, Soreide O (2002) Prognostic significance of the circumferential resection margin following total mesorectal excision for rectal cancer. Br J Surg 89:327-334. https://doi.org/10.1046/j.0007-1323. 2001.02024.X

5. Hashiguchi Y, Muro K, Saito Y, Ito Y, Ajioka Y, Hamaguchi T, Hasegawa K, Hotta K, Ishida H, Ishiguro M, Ishihara S, Kanemitsu Y, Kinugasa Y, Murofushi K, Nakajima TE, Oka S, Tanaka T, Taniguchi $\mathrm{H}$, Tsuji A, Uehara K, Ueno H, Yamanaka T, Yamazaki K, Yoshida M, Yoshino T, Itabashi M, Sakamaki K, Sano K, Shimada Y, Tanaka S, Uetake H, Yamaguchi S, Yamaguchi N, Kobayashi H, Matsuda K, Kotake K, Sugihara K, Japanese Society for Cancer of the C, Rectum (2020) Japanese Society for Cancer of the Colon and Rectum (JSCCR) guidelines 2019 for the treatment of colorectal cancer. Int J Clin Oncol 25:142. https://doi.org/10.1007/s10147-019-01485-Z

6. Watanabe T, Itabashi M, Shimada Y, Tanaka S, Ito Y, Ajioka Y, Hamaguchi T, Hyodo I, Igarashi M, Ishida H, Ishihara S, Ishiguro M, Kanemitsu Y, Kokudo N, Muro K, Ochiai A, Oguchi M, Ohkura Y, Saito Y, Sakai Y, Ueno H, Yoshino T, Boku N, Fujimori T, Koinuma N, Morita T, Nishimura G, Sakata Y, 
Takahashi K, Tsuruta O, Yamaguchi T, Yoshida M, Yamaguchi N, Kotake K, Sugihara K, Japanese Society for Cancer of the C, Rectum (2015) Japanese Society for Cancer of the Colon and Rectum (JSCCR) guidelines 2014 for treatment of colorectal cancer. Int J Clin Oncol 20:207-239. https://doi.org/10.1007/s10147015-0801-Z

7. Fujita S, Akasu T, Mizusawa J, Saito N, Kinugasa Y, Kanemitsu Y, Ohue M, Fujii S, Shiozawa M, Yamaguchi T, Moriya Y, Colorectal Cancer Study Group of Japan Clinical Oncology G (2012) Postoperative morbidity and mortality after mesorectal excision with and without lateral lymph node dissection for clinical stage II or stage III lower rectal cancer (JCOG0212): results from a multicentre, randomised controlled, non-inferiority trial. Lancet Oncol 13:616-621. https://doi.org/10.1016/S1470-2045(12) 70158-4

8. Fujita S, Mizusawa J, Kanemitsu Y, Ito M, Kinugasa Y, Komori K, Ohue M, Ota M, Akazai Y, Shiozawa M, Yamaguchi T, Bandou H, Katsumata K, Murata K, Akagi Y, Takiguchi N, Saida Y, Nakamura K, Fukuda H, Akasu T, Moriya Y, Colorectal Cancer Study Group of Japan Clinical Oncology G (2017) Mesorectal excision with or without lateral lymph node dissection for clinical stage II/III lower rectal cancer (JCOG0212): a multicenter, randomized controlled, noninferiority trial. Ann Surg. https://doi.org/10. 1097/SLA.0000000000002212

9. Akiyoshi T, Watanabe T, Miyata S, Kotake K, Muto T, Sugihara K, Japanese Society for Cancer of the C, Rectum (2012) Results of a Japanese nationwide multi-institutional study on lateral pelvic lymph node metastasis in low rectal cancer: is it regional or distant disease? Ann Surg 255:1129-1134. https://doi.org/10.1097/SLA. 0b013e3182565d9d

10. Ueno H, Mochizuki H, Hashiguchi Y, Hase K (2001) Prognostic determinants of patients with lateral nodal involvement by rectal cancer. Ann Surg 234:190-197. https://doi.org/10.1097/ 00000658-200108000-00008

11. Edge SB, Compton CC (2010) The American Joint Committee on Cancer: the 7th edition of the AJCC cancer staging manual and the future of TNM. Ann Surg Oncol 17:1471-1474. https://doi.org/10. 1245/s10434-010-0985-4

12. Watanabe T, Muro K, Ajioka Y, Hashiguchi Y, Ito Y, Saito Y, Hamaguchi $T$, Ishida $H$, Ishiguro $M$, Ishihara $S$, Kanemitsu $Y$, Kawano H, Kinugasa Y, Kokudo N, Murofushi K, Nakajima T, Oka S, Sakai Y, Tsuji A, Uehara K, Ueno H, Yamazaki K, Yoshida M, Yoshino T, Boku N, Fujimori T, Itabashi M, Koinuma N, Morita T, Nishimura G, Sakata Y, Shimada Y, Takahashi K, Tanaka S, Tsuruta O, Yamaguchi T, Yamaguchi N, Tanaka T, Kotake K, Sugihara K, Japanese Society for Cancer of the C, Rectum (2018) Japanese Society for Cancer of the Colon and Rectum (JSCCR) guidelines 2016 for the treatment of colorectal cancer. Int J Clin Oncol 23:1-34. https://doi.org/10.1007/s10147017-1101-6

13. Moriya Y, Sugihara K, Akasu T, Fujita S (1997) Importance of extended lymphadenectomy with lateral node dissection for advanced lower rectal cancer. World J Surg 21:728-732

14. Yano H, Moran BJ (2008) The incidence of lateral pelvic side-wall nodal involvement in low rectal cancer may be similar in Japan and the West. Br J Surg 95:33-49. https://doi.org/10.1002/bjs.6061

15. Kanemitsu Y, Komori K, Shida D, Ochiai H, Tsukamoto S, Kinoshita T, Moriya Y (2017) Potential impact of lateral lymph node dissection (LLND) for low rectal cancer on prognoses and local control: a comparison of 2 high-volume centers in Japan that employ different policies concerning LLND. Surgery 162:303314. https://doi.org/10.1016/j.surg.2017.02.005

16. Akiyoshi T, Ueno M, Matsueda K, Konishi T, Fujimoto Y, Nagayama S, Fukunaga Y, Unno T, Kano A, Kuroyanagi H, Oya M, Yamaguchi T, Watanabe T, Muto T (2014) Selective lateral pelvic lymph node dissection in patients with advanced low rectal cancer treated with preoperative chemoradiotherapy based on pretreatment imaging. Ann Surg Oncol 21:189-196. https://doi.org/ 10.1245/s10434-013-3216-y

17. Matsusaka S, Ishihara S, Kondo K, Horie H, Uehara K, Oguchi M, Murofushi K, Ueno M, Mizunuma N, Shimbo T, Kato D, Okuda J, Hashiguchi Y, Nakazawa M, Sunami E, Kawai K, Yamashita H, Okada T, Ishikawa Y, Nakajima T, Watanabe T (2015) A multicenter phase II study of preoperative chemoradiotherapy with S-1 plus oxaliplatin for locally advanced rectal cancer (SHOGUN trial). Radiother Oncol 116:209-213. https://doi.org/10.1016/j.radonc. 2015.08.002

18. Morita T, Murata A, Koyama M, Totsuka E, Sasaki M (2003) Current status of autonomic nerve-preserving surgery for mid and lower rectal cancers: Japanese experience with lateral node dissection. Dis Colon Rectum 46:S78-S87; discussion S87-78. https:// doi.org/10.1097/01.DCR.0000089111.95420.BD

19. Moriya Y, Sugihara K, Akasu T, Fujita S (1995) Nerve-sparing surgery with lateral node dissection for advanced lower rectal cancer. Eur J Cancer 31A:1229-1232. https://doi.org/10.1016/09598049(95)00164-e

20. Grinnell RS (1942) The lymphatic and venous spread of carcinoma of the rectum. Ann Surg 116:200-216

21. Kobayashi H, Mochizuki H, Kato T, Mori T, Kameoka S, Shirouzu K, Sugihara K (2009) Outcomes of surgery alone for lower rectal cancer with and without pelvic sidewall dissection. Dis Colon Rectum 52:567-576. https://doi.org/10.1007/DCR. 0b013e3181a1d994

22. Koyama Y, Moriya Y, Hojo K (1984) Effects of extended systematic lymphadenectomy for adenocarcinoma of the rectumsignificant improvement of survival rate and decrease of local recurrence. Jpn J Clin Oncol 14:623-632

23. Georgiou P, Tan E, Gouvas N, Antoniou A, Brown G, Nicholls RJ, Tekkis P (2009) Extended lymphadenectomy versus conventional surgery for rectal cancer: a meta-analysis. Lancet Oncol 10:10531062. https://doi.org/10.1016/S1470-2045(09)70224-4

24. Nagawa H, Muto T, Sunouchi K, Higuchi Y, Tsurita G, Watanabe T, Sawada T (2001) Randomized, controlled trial of lateral node dissection vs. nerve-preserving resection in patients with rectal cancer after preoperative radiotherapy. Dis Colon Rectum 44:1274 1280

25. Ito M, Kobayashi A, Fujita S, Mizusawa J, Kanemitsu Y, Kinugasa Y, Komori K, Ohue M, Ota M, Akazai Y, Shiozawa M, Yamaguchi T, Akasu T, Moriya Y, Colorectal Cancer Study Group of Japan Clinical Oncology G (2018) Urinary dysfunction after rectal cancer surgery: results from a randomized trial comparing mesorectal excision with and without lateral lymph node dissection for clinical stage II or III lower rectal cancer (Japan Clinical Oncology Group Study, JCOG0212). Eur J Surg Oncol 44:463-468. https://doi.org/ 10.1016/j.ejso.2018.01.015

26. Yamaguchi T, Kinugasa Y, Shiomi A, Tomioka H, Kagawa H (2016) Robotic-assisted laparoscopic versus open lateral lymph node dissection for advanced lower rectal cancer. Surg Endosc 30:721-728. https://doi.org/10.1007/s00464-015-4266-y

27. Kapiteijn E, Marijnen CA, Nagtegaal ID, Putter H, Steup WH, Wiggers T, Rutten HJ, Pahlman L, Glimelius B, van Krieken JH, Leer JW, van de Velde CJ, Dutch Colorectal Cancer G (2001) Preoperative radiotherapy combined with total mesorectal excision for resectable rectal cancer. N Engl J Med 345:638-646. https://doi. org/10.1056/NEJMoa010580

28. Lange MM, Marijnen CA, Maas CP, Putter H, Rutten HJ, Stiggelbout AM, Meershoek-Klein Kranenbarg E, van de Velde CJ, Cooperative clinical investigators of the D (2009) Risk factors for sexual dysfunction after rectal cancer treatment. Eur J Cancer 45:1578-1588. https://doi.org/10.1016/j.ejca.2008.12.014

29. Tekkis PP, Cornish JA, Remzi FH, Tilney HS, Strong SA, Church JM, Lavery IC, Fazio VW (2009) Measuring sexual and urinary 
outcomes in women after rectal cancer excision. Dis Colon Rectum 52:46-54. https://doi.org/10.1007/DCR.0b013e318197551e

30. Ogura A, Konishi T, Cunningham C, Garcia-Aguilar J, Iversen H, Toda S, Lee IK, Lee HX, Uehara K, Lee P, Putter H, van de Velde CJH, Beets GL, Rutten HJT, Kusters M, Lateral Node Study C (2019) Neoadjuvant (chemo)radiotherapy with total mesorectal excision only is not sufficient to prevent lateral local recurrence in enlarged nodes: results of the multicenter lateral node study of patients with low cT3/4 rectal cancer. J Clin Oncol 37:33-43. https:// doi.org/10.1200/JCO.18.00032

31. Hirosawa T, Itabashi M, Ohnuki T, Yamaguchi N, Sugihara K, Kameoka S, Japanese Society for Cancer of the C, Rectum Study Group for Pulmonary Metastases from Colorectal C (2013) Prognostic factors in patients undergoing complete resection of pulmonary metastases of colorectal cancer: a multi-institutional cumulative follow-up study. Surg Today 43:494 499. https://doi.org/ 10.1007/s00595-012-0373-8

32. Yun HR, Lee WY, Lee WS, Cho YB, Yun SH, Chun HK (2007) The prognostic factors of stage IV colorectal cancer and assessment of proper treatment according to the patient's status. Int J Color Dis 22:1301-1310. https://doi.org/10.1007/s00384-007-0315-x

33. Tamura H, Shimada Y, Kameyama H, Yagi R, Tajima Y, Okamura T, Nakano M, Nakano M, Nagahashi M, Sakata J, Kobayashi T, Kosugi SI, Nogami H, Maruyama S, Takii Y, Wakai T (2017) Prophylactic lateral pelvic lymph node dissection in stage IV low rectal cancer. World J Clin Oncol 8:412-419. https://doi.org/10. 5306/wjco.v8.i5.412

34. Oh HK, Kang SB, Lee SM, Lee SY, Ihn MH, Kim DW, Park JH, Kim YH, Lee KH, Kim JS, Kim JW, Kim JH, Chang TY, Park SC, Sohn DK, Oh JH, Park JW, Ryoo SB, Jeong SY, Park KJ (2014) Neoadjuvant chemoradiotherapy affects the indications for lateral pelvic node dissection in mid/low rectal cancer with clinically suspected lateral node involvement: a multicenter retrospective cohort study. Ann Surg Oncol 21:2280-2287. https://doi.org/10. 1245/s10434-014-3559-z

35. Ogawa S, Hida J, Ike H, Kinugasa T, Ota M, Shinto E, Itabashi M, Kameoka S, Sugihara K (2016) Selection of lymph node-positive cases based on perirectal and lateral pelvic lymph nodes using magnetic resonance imaging: study of the Japanese Society for Cancer of the Colon and Rectum. Ann Surg Oncol 23:1187-1194. https:// doi.org/10.1245/s10434-015-5021-2

36. Ogawa S, Hida J, Ike H, Kinugasa T, Ota M, Shinto E, Itabashi M, Okamoto T, Sugihara K (2016) The important risk factor for lateral pelvic lymph node metastasis of lower rectal cancer is node-positive status on magnetic resonance imaging: study of the Lymph Node Committee of Japanese Society for Cancer of the Colon and Rectum. Int J Color Dis 31:1719-1728. https://doi.org/10.1007/ s00384-016-2641-3

37. Markl B, Rossle J, Arnholdt HM, Schaller T, Krammer I, Cacchi C, Jahnig H, Schenkirsch G, Spatz H, Anthuber M (2012) The clinical significance of lymph node size in colon cancer. Mod Pathol 25: 1413-1422. https://doi.org/10.1038/modpathol.2012.92

38. Zheng YC, Zhou ZG, Li L, Lei WZ, Deng YL, Chen DY, Liu WP (2007) Distribution and patterns of lymph nodes metastases and micrometastases in the mesorectum of rectal cancer. J Surg Oncol 96:213-219. https://doi.org/10.1002/jso.20826

39. Sato K, Morohashi H, Tsushima F, Sakamoto Y, Miura T, Fujita H, Umemura K, Suzuki T, Tsuruta S, Kura R, Ono S, Aoki M, Hakamada K (2019) Dual energy CT is useful for the prediction of mesenteric and lateral pelvic lymph node metastasis in rectal cancer. Mol Clin Oncol 10:625-630. https://doi.org/10.3892/mco. 2019.1834

Publisher's note Springer Nature remains neutral with regard to jurisdictional claims in published maps and institutional affiliations. 